NBER WORKING PAPER SERIES

\title{
PRODUCT VARIETY AND DEMAND UNCERTAINTY
}

\author{
Dennis W. Carlton \\ James D. Dana, Jr. \\ Working Paper 10594 \\ http://www.nber.org/papers/w10594 \\ NATIONAL BUREAU OF ECONOMIC RESEARCH \\ 1050 Massachusetts Avenue \\ Cambridge, MA 02138 \\ June 2004
}

We would like to thank Susan Athey, Thomas Ross, and Jacques Cremer for useful comments and discussion. The views expressed herein are those of the author(s) and not necessarily those of the National Bureau of Economic Research.

(C)2004 by Dennis W. Carlton and James D. Dana, Jr.. All rights reserved. Short sections of text, not to exceed two paragraphs, may be quoted without explicit permission provided that full credit, including (C) notice, is given to the source. 
Product Variety and Demand Uncertainty

Dennis W. Carlton and James D. Dana, Jr.

NBER Working Paper No. 10594

June 2004

JEL No. D4, D8, L0, L1

\section{$\underline{\text { ABSTRACT }}$}

We show that demand uncertainty leads to vertical product differentiation even when consumers are homogeneous. When a firm anticipates that its inventory or capacity may not be fully utilized, product variety can reduce its expected costs of excess capacity. When the firm offers a continuum of product varieties, the highest quality product has the highest profit margins but the lowest percentage margin, while the lowest quality product has the highest percentage margin but the lowest absolute margin. We derive these results in both a monopoly model and a variety of different competitive models. We conclude with a discussion of empirical predictions together with a brief discussion of supporting evidence available from marketing studies.

Dennis W. Carlton

Graduate School of Business

The University of Chicago

1101 East 58th Street

Chicago, IL 60637

and NBER

dennis.carlton@gsb.uchicago.edu

James D. Dana, Jr.

Department of Management and Strategy

Kellogg School of Management

2001 Sheridan Road

Northwestern University

Evanston, IL 60091

j-dana@kellogg.northwestern.edu 


\section{Introduction}

What determines the breadth of a firm's product line? While prior research on product line, and product variety more generally, focuses on heterogeneity in consumers' preferences or income, we show that when firms supply an uncertain number of consumers, they may offer more than one product even when consumers preferences are homogeneous. Offering multiple products reduces the costs associated with uncertain demand. In particular, firms prefer to use lower quality products to meet speculative demand. In other words, firms limit their inventory of high quality goods and sell low quality goods once their high quality goods have stocked out. Our model helps explain the extent of product differentiation and suggests a rationale for many common retailing practices such as the use of private labels and full product line forcing by manufacturers.

Specific retail examples include grocery stores' offerings of national brands and private labels, their offerings of fresh and frozen meats and seafood, and restaurants' offerings of special entrees in addition to the regular dinner menu. The model also helps to understand how toy retailers decide how many high versus low quality toys to stock and how clothing retailers decide how many designer fashion items versus regular items to stock.

The model can also explain product differentiation in travel and other service industries. For example, airlines must decide how many first class, business, and extra deep coach class seats to put in a passenger airplane. And hotels can be designed so that every room had a view (a long, narrow design) or so that some rooms have views and others don't (by using a wider design): rooms with views clearly cost more given the shadow (land) cost of the scarce view (i.e., the water can only be viewed from exterior rooms on the side of the building facing it). Stadiums can be built with permanent seats (more comfortable) and temporary seats (less comfortable). Similarly, universities must decide how many faculty versus Ph.D. students to use in staffing their undergraduate 
classes, and medical centers must decide how many physician's aids versus doctor's to use in a doctor's office that accepts walk-in patients.

The common elements in these examples are that firms sink costs of production before demand is realized and that firms choose their capacity (or inventory) of high and low quality products with the expectation that the high quality products will be consumed more frequently than low quality products.

The economics and marketing literatures have made big steps in understanding product differentiation, but have exclusively focused on consumer heterogeneity as the reason for variety (see surveys by Eaton and Lipsey, 1989, and Lancaster, 1990). An important part of this literature looks at the product line and pricing decisions of a monopolist engaging in second degree price discrimination when consumers' valuations are correlated with their preference for product quality (see Muss and Rosen, 1978, and the empirical work of Sheperd, 1991).

Our work is also related to the literature in operations management literature on the inventory problem for a multi-product firm when consumers substitute products in response to stockouts (see Mahajan and van Ryzin, 2001, Bassok, Anupindi, and Akella, 1999, and Noonan, 1995). However, this literature has treated the firm's product line as exogenous. A paper by van Ryzin and Mahajan (1999) considers a model of optimal product assortment with stockouts, but they assume stockouts result in lost sales rather than substitution (see also a related paper by Smith and Agrawal, 2000).

In our paper, we show that even when all consumers have the same preferences over product quality, firms may still offer multiple product qualities provided that demand is uncertain. When only two products are feasible, we show that necessary and sufficient conditions for both products to be produced are that demand is uncertain, that the high quality product generates greater absolute consumer surplus and profit, and that the lower quality product generates greater relative surplus and percentage margins. In the next section we show this result when there is a monopoly supplier, and in Section 3 
we show it for a competitive market and a social planner. In Section 4 we generalize the two-product model in Sections 2 and 3 by considering heterogeneous consumer valuations. In Section 5 we characterize the optimal product line for a monopolist when a continuum of products are feasible. This extension helps establish the generality of the results in the two-product model. We show that the highest quality product produced is the one that generates the greatest total surplus (the one that would have been produced if demand were certain) and the lowest quality product produced is the one that maximizes the relative, or percentage surplus. Section 6 concludes with a discussion of empirical implications together with a brief discussion of supporting evidence from marketing studies of margins earned by grocery stores on private label and national brands. Section 6 also discusses the implications of our model for manufacturer-retailer relationships and full-line forcing, one of several important areas for future research.

\section{Monopolist with Two Feasible Product Varieties}

\section{The Model}

In this section we analyze the product line, inventory, and pricing decisions of a monopolist that can produce two vertically differentiated varieties of the same product, a high quality product and a low quality product.

Let $f(x)$ denote the probability distribution function associated with the random variable $x$, the number of identical consumers willing to buy one unit of output (one seat), on the support $[\underline{x}, \bar{x}] \subset \mathfrak{R}^{+}$and suppose $\underline{x}>0$. Let $F(x)$ denote the associated cumulative distribution function.

Each consumer is willing to pay $v_{h}$ for the high quality good and $v_{l}$ for the low quality good. Without loss of generality, we assume $v_{h}>v_{l}$.

The high quality good $\operatorname{costs} c_{h}$ per unit to produce whether or not it is sold. The low quality good costs $c_{l}$ per unit to produce whether or not it is sold. We assume that 
$v_{h}>c_{h}, v_{l}>c_{l}$, and $c_{h}>c_{l}$, since otherwise the product choice problem would be trivial. We normalize the non-sunk costs to zero.

Define $\Delta_{h}=v_{h}-c_{h}$ and $\Delta_{l}=v_{l}-c_{l}$ to be the total or absolute surplus created by the high and low quality product respectively and define $\omega_{h}=\left(v_{h}-c_{h}\right) / v_{h}$ and $\omega_{l}=\left(v_{l}-c_{l}\right) / v_{l}$ to be the percentage or relative surplus created by each product.

This is a model of complete information and we assume throughout that consumers maximize their surplus given the set of available products and prices.

\section{The One-Product Case}

Suppose first that the firm is constrained to produce only the high quality good (or by analogy, only the low quality good). Clearly the firm sets $p_{h}=v_{h}$. Given this price, the firm chooses its inventory, $q_{h}$, to maximize

$$
\max _{q_{h}} \int_{\underline{x}}^{q_{h}} v_{h} x f(x) d x+\int_{q_{h}}^{\infty} v_{h} q_{h} f(x) d x-q_{h} c_{h} .
$$

The first term represents the firm's revenue when realized demand is less than the firm's inventory; the second term represents the firm's revenue when demand exceeds the firm's inventory and it stocks out, and the final term represents that ex ante sunk cost of production.

The first order condition is

$$
v_{h}\left[1-F\left(q_{h}\right)\right]-c_{h}=0 .
$$

This is the well-known newsboy condition. The firm chooses its inventory level to equate the marginal expected revenue of an additional unit of inventory with the marginal cost of inventory. Rearranging this, we can define the firm's optimal inventory as the solution to

$$
\left[1-F\left(q_{h}^{*}\right)\right]=\frac{c_{h}}{v_{h}} .
$$




\section{The Two-Product Case}

Now suppose that the monopolist can produce any amount of both the high quality good and the low quality good and that consumers are free to purchase any of the firm's products that are available when it is their turn to buy. The firm chooses the price and inventory of each product to maximize its expect profit. Note that the one-product solution above is feasible but not necessarily optimal.

The firm's problem is easiest to analyze by first solving the pricing decision. The following lemma shows that in equilibrium, given any positive inventory choices, $p_{h}=v_{h}$ and $p_{l}=v_{l}$. This is intuitive since we expect the firm to extract the entire surplus. While these prices are not optimal for all possible consumer behavior, they are optimal when consumers buy all of the firms' high quality goods before buying any low quality goods, and we show that this always happens in equilibrium.

Lemma: In equilibrium, given any positive inventory choices, the monopolist's prices are $p_{h}=v_{h}$ and $p_{l}=v_{l}$ and consumers buy all of the firms' high quality goods before buying any low quality goods.

Proof: If consumers strictly prefer either good, the firm can increase the price of that good without changing the order of purchase and its profits would increase, so consumers must be indifferent between the goods.

Since they are indifferent, consumers must buy the high quality goods first. Otherwise the firm could increase its profits by lowering the price of high quality goods (since high quality goods have a higher price and the costs are sunk). But if consumers buy low quality goods last, it follows that $p_{l}=v_{l}$; otherwise the firm could raise its profits by increasing $p_{l}$. Since consumers are indifferent between the goods, it follows that $p_{h}=v_{h}$. 
The certain demand case is presented as a benchmark.

Proposition 1: When demand is certain, i.e. $\underline{x}=\bar{x}$, the monopolist produces only high quality goods if $v_{h}-c_{h}>v_{l}-c_{l}\left(\right.$ or $\left.\Delta_{h}>\Delta_{l}\right)$ and only low quality goods if $v_{h}-c_{h}<v_{l}-c_{l}\left(\right.$ or $\left.\Delta_{h}<\Delta_{l}\right)$.

Proof: If demand is certain, the firm's inventory decision solves

$$
\max _{\left\{q_{l}, q_{h}\right\}} v_{h} q_{h}+v_{l} q_{l}-q_{h} c_{h}-q_{l} c_{l}
$$

subject to $q_{h}+q_{l} \leq x$, and $q_{h}, q_{l} \geq 0$, which implies only the higher margin product will be produced.

When demand is certain and $v_{h}-c_{h}=v_{l}-c_{l}$ ( or $\Delta_{h}=\Delta_{l}$ ), the firm is indifferent between producing low quality and high quality goods.

When demand is uncertain, we can use the Lemma, to write the monopolist's inventory choice problem as

$$
\begin{gathered}
\max _{\left\{q_{l}, q_{h}\right\}} \int_{\underline{x}}^{q_{h}} v_{h} x f(x) d x+\int_{q_{h}}^{q_{h}+q_{l}}\left[v_{h} q_{h}+v_{l}\left(x-q_{h}\right)\right] f(x) d x+ \\
\int_{q_{h}+q_{l}}^{\infty}\left[v_{h} q_{h}+v_{l} q_{l}\right] f(x) d x \\
-q_{h} c_{h}-q_{l} c_{l}
\end{gathered}
$$

subject to $q_{h} \geq 0$ and $q_{l} \geq 0$. So the optimal inventories are given by the complementary slackness conditions,

$$
v_{l}\left[1-F\left(q_{h}+q_{l}\right)\right]-c_{l} \leq 0, q_{l} \geq 0
$$

and

$$
v_{h}\left[1-F\left(q_{h}\right)\right]-v_{l}\left[F\left(q_{h}+q_{l}\right)-F\left(q_{h}\right)\right]-c_{h} \leq 0, q_{h} \geq 0,
$$

where at most one inequality can hold with strict inequality in each condition. 
From these optimality conditions we show the following results on the firm's product line decision:

Proposition 2: When demand is uncertain, i.e., $\underline{x}>\bar{x}$, then the monopolist produces (i) only the low quality good if $v_{h}-c_{h}<v_{l}-c_{l}$ (or $\Delta_{h}<\Delta_{l}$ ), (ii) both the high quality good and the low quality good if $v_{h}-c_{h}>v_{l}-c_{l}\left(\right.$ or $\left.\Delta_{h}>\Delta_{\nu}\right)$ and

$$
\frac{c_{h}}{v_{h}}>\frac{c_{l}}{v_{l}} \text { (or equivalently } 1-\frac{c_{h}}{v_{h}}<1-\frac{c_{l}}{v_{l}} \text { ) }
$$

(or $\omega_{h}<\omega_{l}$ ) and (iii) only the high quality good if $v_{h}-c_{h}>v_{l}-c_{l}\left(\right.$ or $\Delta_{h}>\Delta_{l}$ ) and

$$
\frac{c_{h}}{v_{h}}<\frac{c_{l}}{v_{l}}
$$

$\left(\right.$ or $\left.\omega_{h}>\omega_{l}\right)$.

Proof. First, let $v_{l}-c_{l}>v_{h}-c_{h}$. If $q_{h}>0$, then either $q_{l}=0$ and $q_{h}>0$ or $q_{l}>0$ and $q_{h}>0$. Suppose $q_{l}=0$ and $q_{h}>0$. Then (a) and (b) become $v_{l}\left[1-F\left(q_{h}\right)\right]-c_{l} \leq 0$ and $v_{h}\left[1-F\left(q_{h}\right)\right]-c_{h}=0$, which is a contradiction. Suppose instead that $q_{l}>0$ and $q_{h}>0$. Then (a) and (b) hold with equality. Subtracting (a) from (b) yields $\left[v_{h}-v_{l}\right]\left[1-F\left(q_{h}\right)\right]=c_{h}-c_{l}$, so

$$
1-F\left(q_{h}\right)=\frac{c_{h}-c_{l}}{v_{h}-v_{l}}>1
$$

or equivalently $F\left(q_{h}\right)<0$, which is a contradiction. So $v_{l}-c_{l}>v_{h}-c_{h}$ implies $q_{h}=0$. This implies the following complementary slackness condition

$$
\left[1-F\left(q_{l}\right)\right] \leq \frac{c_{l}}{v_{l}}, q_{l} \geq 0
$$

and since $c_{l} / v_{l}<1$, it follows that so $q_{l}>0$. So $q_{h}=0$ and $q_{l}>0$.

Next let $v_{h}-c_{h}>v_{l}-c_{l}$. If $q_{h}=0$, then either $q_{l}=0$ and $q_{h}=0$ or $q_{l}>0$ and $q_{h}=0$. Suppose that $q_{l}=0$ and $q_{h}=0$. Then (a) and (b) imply $v_{l}-c_{l} \leq 0$ and 
$v_{h}-c_{h} \leq 0$ which is a contradiction. Suppose instead $q_{l}>0$ and $q_{h}=0$. Then (a) and (b) become $v_{l}\left[1-F\left(q_{l}\right)\right]-c_{l}=0$ and $v_{h}-v_{l} F\left(q_{h}\right)-c_{h} \leq 0$, which is a contradiction. So $v_{h}-c_{h}>v_{l}-c_{l}$ implies $q_{h}>0$.

Now let $v_{h}-c_{h}>v_{l}-c_{l}$ and

$$
\frac{c_{l}}{v_{l}}>\frac{c_{h}}{v_{h}}
$$

The later implies that $v_{h} c_{l}>v_{l} c_{h}$, so $v_{h} c_{l}-v_{l} c_{l}>v_{l} c_{h}-v_{l} c_{l}$ or

$$
\frac{c_{l}}{v_{l}}>\frac{c_{h}-c_{l}}{v_{h}-v_{l}}
$$

If $q_{l}>0$, then (a) and (b) can be rewritten as

$$
v_{l}\left[1-F\left(q_{h}+q_{l}\right)\right]-c_{l}=0
$$

and

$$
\left[1-F\left(q_{h}\right)\right]=\frac{c_{h}-c_{l}}{v_{h}-v_{l}}
$$

but these and (e) imply

$$
\left[1-F\left(q_{h}+q_{l}\right)\right]=\frac{c_{l}}{v_{l}}>\frac{c_{h}-c_{l}}{v_{h}-v_{l}} \geq\left[1-F\left(q_{h}\right)\right]
$$

which implies $q_{l} \leq 0$, which is a contradiction. So $v_{h}-c_{h}>v_{l}-c_{l}$ and

$$
\frac{c_{l}}{v_{l}}>\frac{c_{h}}{v_{h}}
$$

imply $q_{h}>0$ and $q_{l}=0$.

Finally, let $v_{h}-c_{h}>v_{l}-c_{l}$ and

$$
\frac{c_{h}}{v_{h}}>\frac{c_{l}}{v_{l}} .
$$

The later implies 


$$
\frac{c_{h}-c_{l}}{v_{h}-v_{l}}>\frac{c_{l}}{v_{l}}
$$

If $q_{l}=0$, then (a) and (b) can be rewritten as

$$
v_{l}\left[1-F\left(q_{h}+q_{l}\right)\right]-c_{l} \leq 0
$$

and

$$
\left[1-F\left(q_{h}\right)\right]=\frac{c_{h}-c_{l}}{v_{h}-v_{l}}
$$

but these and (f) imply

$$
\left[1-F\left(q_{h}+q_{l}\right)\right] \leq \frac{c_{l}}{v_{l}}<\frac{c_{h}-c_{l}}{v_{h}-v_{l}}=\left[1-F\left(q_{h}\right)\right]
$$

which implies $q_{l}>0$, which is a contradiction. So $v_{h}-c_{h}>v_{l}-c_{l}$ and

$$
\frac{c_{h}-c_{l}}{v_{h}-v_{l}}>\frac{c_{l}}{v_{l}}
$$

imply $q_{h}>0$ and $q_{l}=0$.

If $v_{l}-c_{l}=v_{h}-c_{h}$ the firm is indifferent between offering only the low quality good and both the high and low quality good, and if $v_{h}-c_{h} \geq v_{l}-c_{l}$ and

$$
\frac{c_{l}}{v_{l}}=\frac{c_{h}}{v_{h}}
$$

then the firm is indifferent between offering only the high quality good and both the high and low quality goods. Both of these equalities hold only in the case in which $v_{l}=c_{l}$ and $v_{h}=c_{h}$, in which case there is no surplus and the firm is indifferent between producing either good and producing nothing.

Figures 1 and 2 shows the optimal product line as a function of the costs of each product holding consumers' valuations for the products fixed (we could have presented similar figures holding cost fixed and varying the valuations). Figure 1 shows graphically that when demand is certain, the decision to produce the high quality good versus the low 
quality good depends only on the relative magnitude absolute markups, $\Delta_{h}=v_{h}-c_{h}$ and $\Delta_{l}=v_{l}-c_{l}$. The shaded regions are irrelevant for our analysis in that these are parameter values which violate our starting assumptions for the problem (we assumed that the low quality good was cheaper to produce and both goods could profitable be produced).

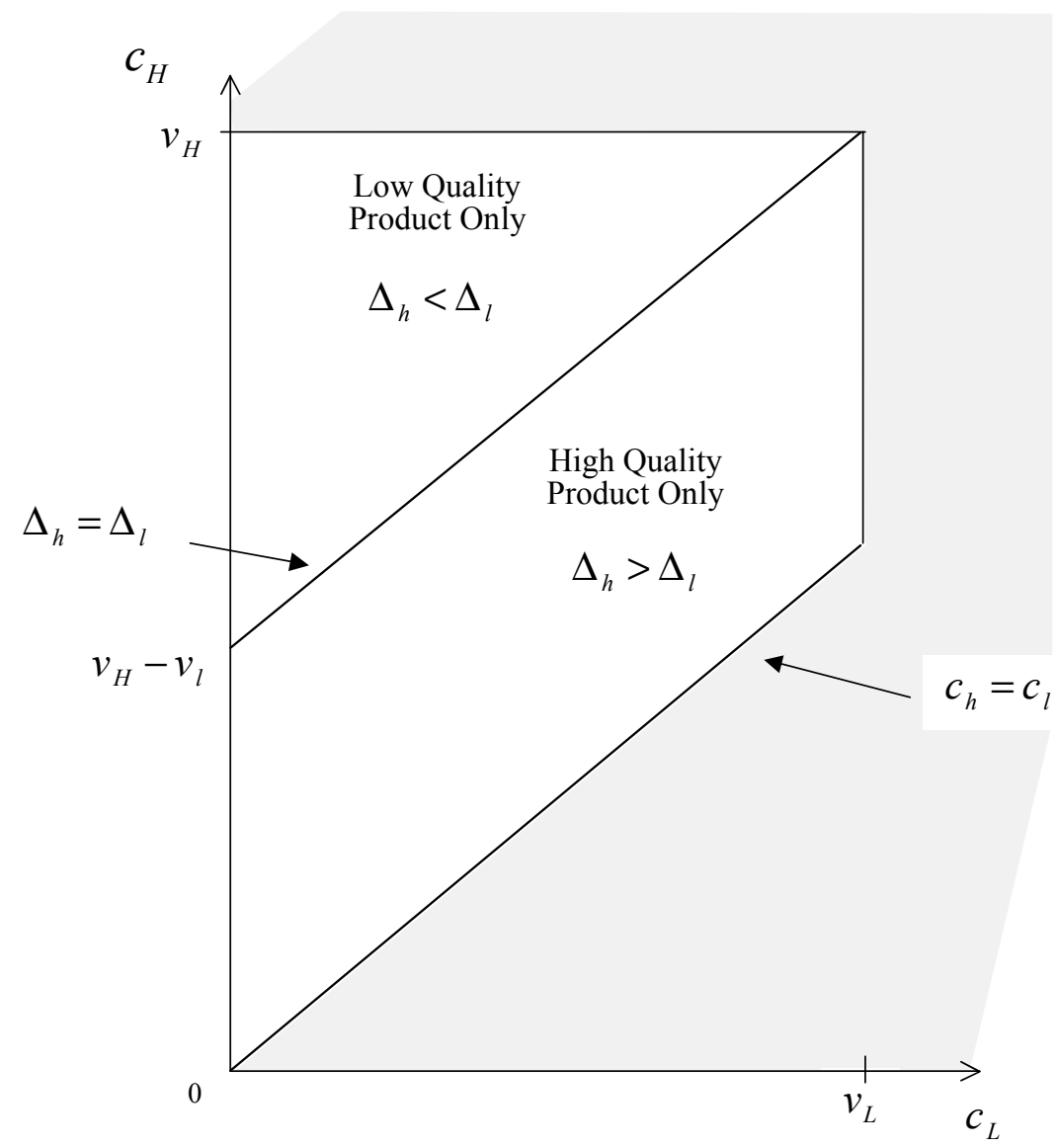

Figure 1: Product Line as a Function of Product Costs (Certain Demand)

Figure 2 shows graphically that when demand is uncertain, the decision to produce the high quality good versus the low quality good depends both on which product has the higher total or absolute markups, $\Delta_{h}=v_{h}-c_{h}$ and $\Delta_{l}=v_{l}-c_{l}$, and on which product has the higher relative or percentage markups, $\omega_{h}=1-c_{h} / v_{h}$ and $\omega_{l}=1-c_{l} / v_{l}$. If low quality goods have a higher absolute and percentage markup they are the only goods produced. Similarly, if high quality goods have a higher absolute and 
percentage markup they are the only goods produced. But when the high quality good has a greater absolute margin and the low quality good has a higher percentage margin, then both products are produced.

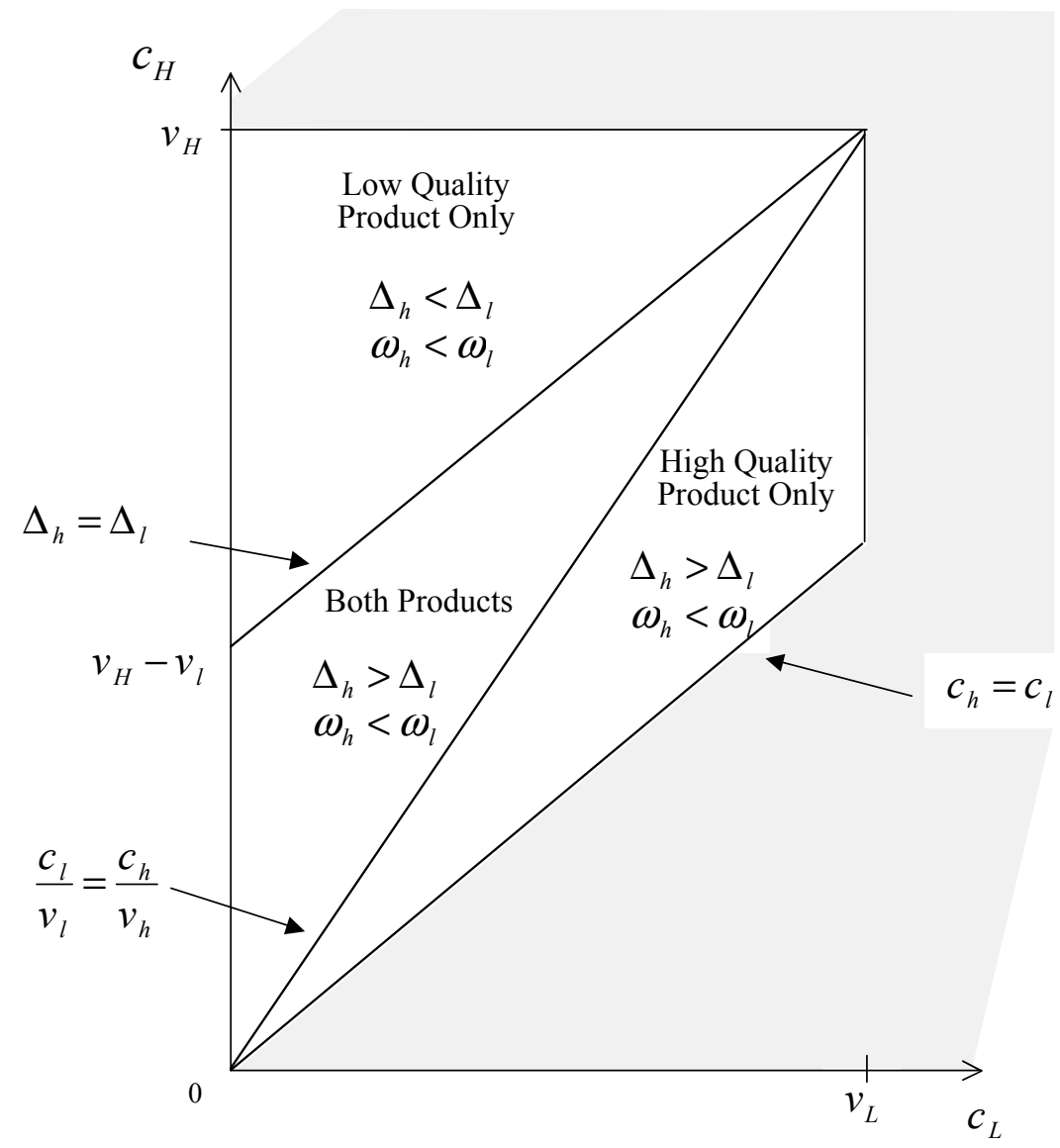

Figure 2: Product Line as a Function of Product Costs (Uncertain Demand)

Figure 3 provides the intuition for Proposition 2. For the case in which it is optimal to produce both products, the Figure depicts the optimal production, $q_{h}^{* *}$ and $q_{l}^{* *}$ in terms of the first order conditions for the single product firm. First notice that if the firm were to produce $q_{h}^{*}$ units of the high quality good and no units of the low quality good. the marginal return to adding a low quality unit the same as the marginal return to adding a low quality unit if the firm were to produce $q_{h}^{*}$ units of the low quality good, and this is clearly positive. So the firm's optimal total output is clearly defined by 
$v_{l}[1-F(q)]-c_{l}=0$ and clearly exceeds $q_{h}^{*}$. Second, notice that if only the high quality product were produced, the optimal choice of output, $q_{h}^{*}$, exceeds $q_{h}^{* *}$. The reason $q_{h}^{* *}<q_{h}^{*}$ is that when the firm is producing both products, an extra unit of the high quality output imposes an additional cost on the firm because it lowers the expected sales of the low quality units. So there is an incentive to reduce $q_{h}$ below the single product optimum.

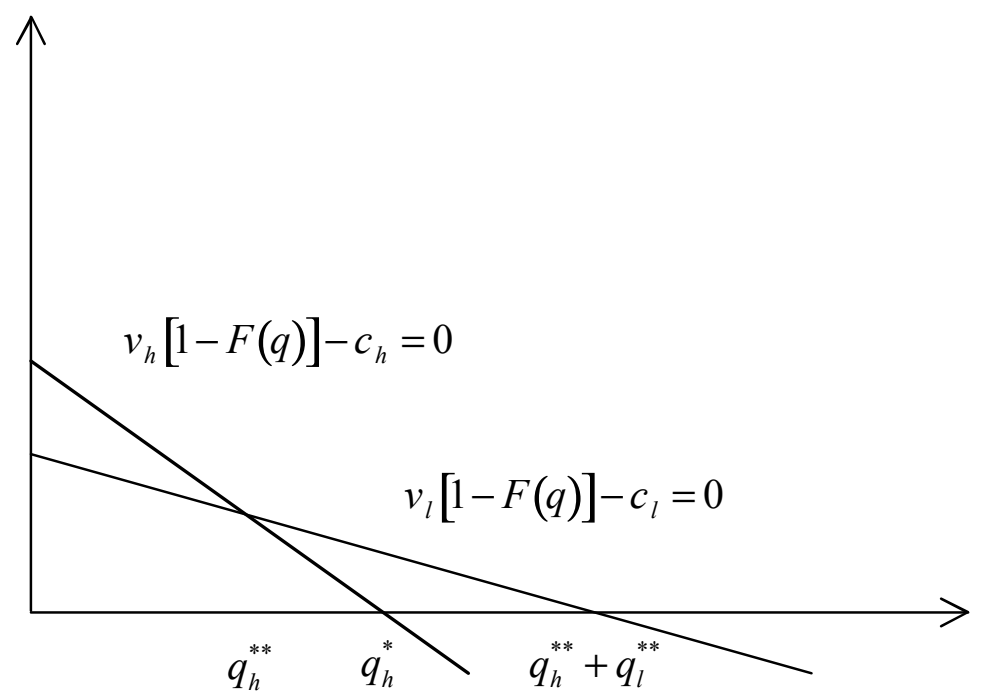

Figure 3: Graphs of the First Order Conditions from Proposition 2

Proposition 2 implies the following interesting and empirically testable corollary about product lines.

Corollary: If the monopolist produces two products then the higher quality product must have a higher absolute margin and lower percentage margin: $q_{h}>0$ and $q_{l}>0$ $\Rightarrow p_{h}-c_{h}>p_{l}-c_{l} \&\left(p_{h}-c_{h}\right) / p_{h}<\left(p_{l}-c_{l}\right) / p_{l}$.

\section{Competitive Markets with Two Product Varieties}

In this section we again suppose that firms can produce only two vertically differentiated varieties of the same product model, but here we allow a continuum of 
competitive firms to supply the market. The same two products are feasible and the unit costs and consumer valuations are the same as in the monopoly analysis.

There are a number of different ways to model competition with demand uncertainty, each of which is realistic for some markets and each of which can imply very different understandings of how market operate. We examine three different models of competition and show that results similar to those in the previous models apply to all three models. In Section 3.1 we assume that prices clear the market after demand is realized. In Section 3.2 we assume that prices are set before demand is realized and that consumers can search costlessly for price and availability. In Section 3.3 we also assume that prices are set before demand is realized, but assume that consumers can visit only one firm (but choose the firm to visit based on price and availability).

The market allocations in the three competitive models turn out to be the same. This isn't that surprising since in all three competitive models the choice of product variety is efficient (though this is a consequence of assuming homogeneous consumers and unit demands, see Dana, 1998, and Eden, working paper). Under these conditions, the three competitive equilibrium allocations are also the same as in the monopoly problem above. We relax the unit demand assumption in Section 4.

The following propositions, analogous to Propositions 1 and 2, hold for all three models.

Proposition 3: When demand is certain, i.e. $\underline{x}=\bar{x}$, then in equilibrium competitive firms produce only high quality goods if $v_{h}-c_{h}>v_{l}-c_{l}$ and only low quality goods if $v_{h}-c_{h}<v_{l}-c_{l}$.

Proposition 3 follows from marginal cost pricing. 
Proposition 4: When demand is uncertain, i.e., $\underline{x}<\bar{x}$, then competitive firms produce (i) only the low quality good if $v_{l}-c_{l}>v_{h}-c_{h}$; (ii) both the high quality good and the low quality good if $v_{h}-c_{h}>v_{l}-c_{l}$ and

$$
\frac{c_{h}}{v_{h}}>\frac{c_{l}}{v_{l}}
$$

and (iii) produce only the high quality good if $v_{h}-c_{h}>v_{l}-c_{l}$ and

$$
\frac{c_{l}}{v_{l}}>\frac{c_{h}}{v_{h}}
$$

In each case, though the definition of competitive equilibrium changes slightly, we show that conditions (a) and (b) hold. Proposition 4 (the proof is the same as Proposition 2) follows from (a) and (b).

Finally, since Figure 1 follows from (a) and (b), it also depicts the equilibrium product line offerings in a competitive market.

\subsection{Market Clearing}

We begin with a definition of a competitive equilibrium.

A competitive equilibrium is the ex ante levels of market production, $q_{h}$ and $q_{l}$, a set of state-contingent spot market prices, $p_{h}(x)$ and $p_{l}(x)$ and spot market sales such that (i) firms sell in the spot market no more than they produce ex ante, (ii) if the spot market price is positive firms sell all that they produced ex ante, (iii) firms cannot increase their expected profits by producing more ex ante.

When demand is certain, clearly prices are equal to marginal cost, so Proposition 3 holds. When demand is uncertain, we begin with the case where only one product is feasible.

If only one product were feasible, say the high quality product, then when $q_{h} \geq x$ the spot market price is zero and sales are $x$ and when $q_{h}<x$ the spot market price is $v_{h}$ 
and sales are $q_{h}$. Since the incremental profits from additional units of ex ante demand must be zero, $q_{h}$ is determined by

$$
c_{h}=\int_{q_{h}}^{\infty} v_{h} f(x) d x
$$

It follows that

$$
v_{h}\left[1-F\left(q_{h}\right)\right]-c_{h}=0 .
$$

Now suppose that two products are feasible. We begin by characterizing the equilibrium spot market prices and sales given $q_{h}$ and $q_{l}$.

When $x \leq q_{h}$, the spot market price of high and low quality units will be zero and only high quality units will sell because all consumers strictly prefer high quality. The shadow cost of both high and low quality is zero.

When $q_{h}<x \leq q_{l}+q_{h}$, the spot market price for low quality is zero and sales of low quality units are $x-q_{l}$. If the price were positive, then sales of the high quality units would be less than $q_{h}$ which implies the price of high quality units is zero, but since consumers strictly prefer high quality units, the demand for low quality units would be zero, which is inconsistent with a positive price for low quality units. It follows that the price of high quality units must be $v_{h}-v_{l}$ and firms sell every unit produced

When $q_{l}+q_{h}<x$, the spot market price for high quality units is $v_{h}$ and the spot market price for low quality units is $v_{l}$ and firms sell every unit produced.

Since the incremental profits from additional units of ex ante production of low quality units must be zero, $q_{l}$ is determined by

$$
c_{l}=\int_{q_{h}+q_{l}}^{\infty} v_{l} f(x) d x .
$$

And since the incremental profits from additional units of ex ante production of low quality units must be zero, $q_{l}$ is determined by

$$
c_{h}=\int_{q_{l}}^{q_{h}+q_{l}}\left(v_{h}-v_{l}\right) f(x) d x+\int_{q_{h}+q_{l}}^{\infty} v_{h} f(x) d x .
$$


So

$$
v_{l}\left[1-F\left(q_{h}+q_{l}\right)\right]-c_{l} \leq 0, q_{l} \geq 0
$$

and

$$
v_{h}\left[1-F\left(q_{h}\right)\right]-v_{l}\left[F\left(q_{h}+q_{l}\right)-F\left(q_{h}\right)\right]-c_{h} \leq 0, q_{h} \geq 0
$$

which implies Proposition 4 holds when markets are in equilibrium.

\subsection{Rigid Prices and Flexible Consumer Choice}

In this Section and Section 3.3, we assume that the firms set their prices before learning demand. This assumption seems appropriate for some of the examples discussed in the introduction, such as restaurants. Moreover price rigidities increase the likelihood that capacity is not utilized when demand realizations are low, and hence increase the likelihood that the use of quality dispersion will be the optimal policy to follow. We will see, however, that in the case of unit demands the equilibrium product variety is the same with and without price rigidities.

In this Section, we assume that consumers can observe and costlessly choose among all available products and prices when they make their purchase decisions. Consumers make their purchases sequentially (they are identical so the order doesn't matter) so this means that when it is a consumer's turn to purchase, he or she is able to purchase the best remaining price-product combination offered by any firm.

This zero shopping cost assumption is not always realistic. Moreover, because of this assumption this model predicts only the market availability of products and not the product line of individual firms. In equilibrium, all firms could be specialists in either high quality or low quality, or all could offer both high and low quality goods. We change this assumption in Section 3.3.

This model is a multi-product extension of a model introduced by Prescott (1976), formalized by Eden (1990), and applied by Dana (2000). 
In this environment a competitive equilibrium is a set of market prices, associated probabilities of sale, and ex ante quantity choices such that (i) firms cannot increase their profits by changing their ex ante output given the prices and associated probabilities of sale and (ii) the probability of sale associated with each price is consistent with prices, quantities, and market demand, (iii) consumers

When demand is certain all firms charge marginal cost in equilibrium, so Proposition 3 holds. When demand is uncertain, the competitive equilibrium will consist of a range of prices for each good offered. From profit maximization, i.e., the zero-profit condition, it follows that if a low quality good is offered at price $p$ the probability that it sells in equilibrium must be $c_{l} / p$. However firms may not offer positive output at all prices in equilibrium.

In state $x$, goods with a probability of sale greater than or equal to $1-F(x)$ must sell. From the zero profit condition, we know low quality goods priced at

$$
\frac{c_{l}}{1-F(x)}
$$

and high quality goods priced at

$$
\frac{c_{h}}{1-F(x)}
$$

are the "last" units to sell in state $x$. However, consumers prefer high quality goods if

$$
v_{h}-\frac{c_{h}}{1-F(x)}>v_{l}-\frac{c_{l}}{1-F(x)}
$$

and prefer low quality goods otherwise. When high quality goods are preferred, profit maximization implies that only high quality goods will be produced. So when this expression holds at $\underline{x}$, i.e., $v_{h}-c_{h}>v_{l}-c_{l}$, the total supply of high quality goods will be the quantity that equalizes this expression: 


$$
v_{h}-\frac{c_{h}}{1-F\left(q_{h}\right)}=v_{l}-\frac{c_{l}}{1-F\left(q_{h}\right)}
$$

In higher demand states, consumers prefer low quality goods, but only if the price is less than $v_{l}$. It follows that

$$
\frac{c_{l}}{1-F\left(q_{h}+q_{l}\right)}=v_{l}
$$

This implies that (a) and (b) are satisfied, so Proposition 4 holds for rigid prices when consumers have flexible choice.

\subsection{Rigid Prices with Inflexible Choice}

In this section, consumers must commit to purchase from a single firm before they learn whether the firm's products are available. Consumers choose given only ex ante information about firms' products, prices, and inventories. If the firm that a consumer visits stocks out of a consumer's preferred product, the consumer either buys another product from the same firm or nothing at all. So consumers visit the firm that offers the greatest expect consumer surplus. In equilibrium, competitive firms compete this surplus down to zero.

A symmetric competitive equilibrium is a pair of prices and production levels and a set of active firms such that no combination of prices and production levels exists that would increase consumers' surplus if every consumer switched to the deviating firm.

This model is a multi-product extension of Carlton (1978) ${ }^{1}$. Since firms have no market power, the equilibrium prices and inventories are those that maximize consumer surplus plus producer surplus subject to a zero profit constraint and non-negative ex ante and ex post consumer surplus constraints. In addition, if a firm offers both products it

\footnotetext{
${ }^{1}$ See Deneckere and Peck (1995) for an analysis of this game with a finite number of firms. They show that Carlton's equilibrium is the limit of the subgame perfect Nash equilibrium of the oligopoly game as the number of firms goes to infinity.
} 
must be the case that consumers buy high quality goods before they buy low quality goods. If consumers behaved otherwise, the firm would be able to make a profitable deviation that would induce the efficient purchase order.

So we can write the firm's problem as ${ }^{2}$

$$
\begin{gathered}
\max _{\left\{q_{l}, q_{h}, p_{l}, p_{h}\right\}} \int_{0}^{q_{h}} v_{h} x f(x) d x+\int_{q_{h}}^{q_{h}+q_{l}}\left[v_{h} q_{h}+v_{l}\left(x-q_{h}\right)\right] f(x) d x \\
+\int_{q_{h}+q_{l}}^{\infty}\left[v_{h} q_{h}+v_{l} q_{l}\right] f(x) d x \\
-q_{h} c_{h}-q_{l} c_{l}
\end{gathered}
$$

subject to $q_{h} \geq 0, q_{l} \geq 0$, a zero profit constraint,

$$
\begin{gathered}
\int_{0}^{q_{h}} p_{h} x f(x) d x+\int_{q_{h}}^{q_{h}+q_{l}}\left[p_{h} q_{h}+p_{l}\left(x-q_{h}\right)\right] f(x) d x \\
+\int_{q_{h}+q_{l}}^{\infty}\left[p_{h} q_{h}+p_{l} q_{l}\right] f(x) d x-q_{h} c_{h}-q_{l} c_{l}=0,
\end{gathered}
$$

ex post consumer surplus constraints: $p_{l} \leq v_{l}$ and $p_{h} \leq v_{h}$, a purchase ordering constraint: $v_{h}-p_{h} \geq v_{l}-p_{l}$, and an ex ante consumer surplus constraint:

$$
\begin{gathered}
\int_{0}^{q_{h}}\left(v_{h}-p_{h}\right) g(x) d x+\int_{q_{h}}^{q_{h}+q_{l}} \frac{\left[\left(v_{h}-p_{h}\right) q_{h}+\left(v_{l}-p_{l}\right)\left(x-q_{h}\right)\right]}{x} g(x) d x \\
+\int_{q_{h}+q_{l}}^{\infty} \frac{\left[\left(v_{h}-p_{h}\right) q_{h}+\left(v_{l}-p_{l}\right) q_{h}\right]}{x} g(x) d x \geq 0,
\end{gathered}
$$

where $g$ is the probability distribution function for the demand state given that a random consumer actually wants the good. Note that the ex ante consumer surplus constraint is satisfied as long as the ex post constraints, $p_{l} \leq v_{l}$ and $p_{h} \leq v_{h}$, are satisfied, so it is not binding. Also, $p_{h} \leq v_{h}$ and $v_{h}-p_{h} \geq v_{l}-p_{l}$ imply $p_{l} \leq v_{l}$, so we can ignore this constraint.

\footnotetext{
${ }^{2}$ Since $f$ is distribution of aggregate demand and $q$ denotes total output, the individual firm's problem profit function is proportional to this aggregate profit function.
} 
Consider the firm's unconstrained production problem subject only to $q_{h} \geq 0$ and $q_{l} \geq 0$. The complementary slackness conditions are

$$
\left(v_{h}-v_{l}\right)\left[F\left(q_{h}+q_{l}\right)-F\left(q_{h}\right)\right]+v_{h}\left[1-F\left(q_{h}+q_{l}\right)\right]-c_{h} \geq, q_{h} \geq 0
$$

and

$$
v_{l}\left[1-F\left(q_{h}+q_{l}\right)\right]-c_{l} \geq 0, q_{l} \geq 0,
$$

which imply that both (a) and (b) hold. However we must verify that the omitted constraints are satisfied. That is, we must verify that given (a) and (b) there exist prices such that $p_{h} \leq v_{h}, v_{h}-p_{h} \geq v_{l}-p_{l}$, and zero-profit constraint holds.

It is natural to suppose the equilibrium prices will be the ones that equate the total revenues from sales of each product to the total costs of producing that product. In this case the zero profit constraint holds by construction. The price $p_{l}$ is defined by

$$
\int_{0}^{q_{h}} p_{h} x f(x) d x+p_{h} q_{h}\left[1-F\left(q_{h}\right)\right]-q_{h} c_{h}=0
$$

and the price $p_{h}$ is defined by

$$
\int_{q_{h}}^{q_{h}+q_{l}} p_{l}\left(x-q_{h}\right) f(x) d x+p_{l} q_{l}\left[1-F\left(q_{h}+q_{l}\right)\right]-q_{l} c_{l}=0 .
$$

We can rewrite these equations as

$$
p_{h}\left[\int_{0}^{q_{h}} \frac{x}{q_{h}} f(x) d x+\left[1-F\left(q_{h}\right)\right]\right]-c_{h}=0
$$

and

$$
p_{l}\left[\int_{q_{h}}^{q_{h}+q_{l}} \frac{x-q_{h}}{q_{l}} f(x) d x+\left[1-F\left(q_{h}+q_{l}\right)\right]\right]-c_{l}=0
$$

where the bracketed expressions are the average probability of sale of the high and low quality goods respectively. 
From (a) and (b) we know

$$
v_{h}\left[1-F\left(q_{h}\right)\right]-c_{h} \geq 0
$$

and the inequality is strict if $q_{l}>0$. Since

$$
\int_{0}^{q_{h}} \frac{x}{q_{h}} f(x) d x>0,
$$

(g) implies that $v_{h}>p_{h}$ whenever $q_{h}$ and $q_{l}$ are positive.

If $q_{h}$ is positive then (a) and (b) imply $v_{h}-c_{h} \geq v_{l}-c_{l}$, so

$$
\frac{v_{h}}{p_{h}}-\frac{c_{h}}{p_{h}} \geq \frac{v_{l}}{p_{l}}-\frac{c_{l}}{p_{l}}
$$

And, since in each demand state the probability of sale of a high quality good is strictly greater than the probability of sale of a low quality good, it must be that the average probability of sale is greater for high quality goods, which with $(\mathrm{g})$ and $(\mathrm{h})$ imply that

$$
\frac{c_{l}}{p_{l}}>\frac{c_{h}}{p_{h}}
$$

So

$$
\frac{v_{h}}{p_{h}}>\frac{v_{l}}{p_{l}}
$$

and since $v_{h} \geq v_{l}$, it follows that $v_{h}-p_{h}>v_{l}-p_{l}$.

So all of the omitted constraints are satisfied by the solution (a), (b), (g) and (h) and Proposition 4 holds.

However the equilibrium in this model does not yield unique individual prices. The prices defined by (g) and (h) are natural, but they are not unique. The firms could also subsidize their low quality goods and charge a premium for high quality as long as its inventory satisfied (a) and (b) and $v_{h}-p_{h}>v_{l}-p_{l}>0$. Prices only role here is to attract consumers to the store and there are many price pairs that induce the same 
consumer behavior. Furthermore, different firms can offer different prices in equilibrium.

Proposition 5: All competitive equilibrium of the inflexible choice, rigid price model satisfy (a) and (b).

While the prices $p_{l}$ and $p_{h}$ are not uniquely determined, they must be nonnegative, they must be less than $v_{l}$ and $v_{h}$ respectively, and they must induce consumers to weakly prefer the high quality item.

\section{The Two-Product Model with Downward Sloping Demand}

In this section we extend the two-product model by considering heterogeneity in consumers' valuations. This is particularly valuable because any empirical test of our theory of product variety will need to consider heterogeneous consumers. Also it is important to see that two-product models considered in Sections 2 and 3 will no longer yield the same equilibrium allocation when consumers are heterogeneous. This is because both market power and ex ante pricing are contributing to the deadweight loss when consumers are heterogeneous. Market power imposes costs for the usual reason. Ex ante pricing imposes costs because it is possible that consumers with the highest valuation of the good may find the good unavailable even while consumers with lower valuations were able to buy the good. For this reason, we begin by characterizing the social planner's problem and then show that this is the market allocation associated with market clearing prices.

Let $f$ denote the distribution of $x$, the number of identical consumers willing to pay $v$ for the high quality good and $v-s$ for the low quality good. Consumers know their own valuations conditional on wanting the good, but don't learn whether or not they want the good until after the planner has chosen its inventory. The distribution of consumer valuations in the population is given probability density function $h$ and cumulative 
density function $H$. Each consumer who wants a good will buy at most one. As before, high quality goods $\operatorname{cost} c_{h}$ to produce whether or not they are used. Low quality goods $\operatorname{cost} c_{l}$ to produce whether or not they are used. We assume that $s>c_{h}-c_{l}$, so given certain demand (e.g., $\underline{x}=\bar{x}$ ) only the high quality product would be produced.

We assume that $x$ and $v$ are independently distributed. In other words, an individual's valuation is not correlated with the probability that they want the good. This assumption implies that there is no role for screening in the product line decision of firms. If screening were possibly, then it alone would offer a justification for product variety.

If the social planner can produce only one good it would produce the high quality good and the remaining problem would be to choose price, $p_{h}$, and inventory, $q_{h}$, to maximize

$$
\max _{q_{h}} \int_{\underline{x}}^{\max \left(q_{h}, \underline{x}\right)} x \int_{0}^{\infty} v h(v) d v f(x) d x+\int_{\max \left(q_{h}, \underline{x}\right)}^{\infty} x \int_{H^{-1}\left(1-\frac{q_{h}}{x}\right)}^{\infty} v h(v) d v f(x) d x-q_{h} c_{h} .
$$

The first term characterizes consumer surplus when $x$ consumers want the good and $q_{h} \geq x$ are available. In this case everyone gets the good and total surplus is $x E[v]$. The second term characterizes consumer surplus when $x$ consumers want the good and only $q_{h}<x$ are available. In this case only consumers whose valuations are sufficiently high get the good. The cutoff is the valuation of the marginal consumer in state $x$, which is defined by equating total consumption to the planner's capacity:

$$
q_{h}=[1-H(v)] x,
$$

or

$$
v=H^{-1}\left(1-\frac{q_{h}}{x}\right)
$$

The first order condition is 


$$
-\int_{\max \left(q_{h}, \underline{x}\right)}^{\infty} x H^{-1}\left(1-\frac{q_{h}}{x}\right) h\left(H^{-1}\left(1-\frac{q_{h}}{x}\right)\right) \frac{d H^{-1}\left(1-\frac{q_{h}}{x}\right)}{d q_{h}} f(x) d x-c_{h}=0
$$

or

$$
\int_{\max \left(q_{h}, \underline{x}\right)}^{\infty} H^{-1}\left(1-\frac{q_{h}}{x}\right) f(x) d x=c_{h} .
$$

Let $q_{h}^{*}$ denote the solution to (y). The social cost of capacity is set equal to the expected valuation of the marginal consumer (which is zero when the marginal consumer doesn't exist).

Note that the marginal consumer exists in every demand state if and only if $q_{h}^{*} \leq \underline{x}$. When $q_{h}^{*}>\underline{x}$ then there exist low demand states in which everyone who wants the good has it, and there are no additional consumers available to derive utility from consuming the good.

We now turn to the case where the planner can offer two goods. Here the order of consumption may matter. When all of the goods are consumed, efficiency requires that the consumers with the highest valuations obtain the good but it does not matter which consumers get the high quality good; each consumer values quality the same. However when demand is insufficient to fully utilize the available capacity, efficiency requires that the consumers with the highest valuations get the good and that all of the high quality goods be consumed before any of the low quality goods are consumed.

Using this observation about the allocation of the goods ex post we can write the social planner's problem as:

$$
\begin{gathered}
\max _{\left\{q_{h}, q_{l}\right\}} \int_{\underline{x}}^{\max \left(q_{h}, \underline{x}\right)} x \int_{0}^{\infty} v h(v) d v f(x) d x+\int_{\max \left(q_{h}, \underline{x}\right)}^{\max \left(q_{h}+q_{l}, \underline{x}\right)}\left[x \int_{0}^{\infty} v h(v) d v-\left(x-q_{h}\right) s\right] f(x) d x \\
+\int_{\max \left(q_{h}+q_{l}, \underline{x}\right)}^{\infty}\left[x \int_{H^{-1}\left(1-\frac{q_{h}+q_{l}}{x}\right)}^{\infty} v h(v) d v-q_{l} s\right] f(x) d x-q_{h} c_{h}-q_{l} c_{l}
\end{gathered}
$$

The first term characterizes consumer surplus when $x$ consumers want the good and $q_{h} \geq x$ are available. In this case everyone gets the high quality good and total 
surplus is $x E[v]$. The second term characterizes consumer surplus when $x$ consumers want the good and only $q_{h}<x \leq q_{h}+q_{l}$ are available. In this case everyone gets a good, but $x-q_{h}$ consumers get the low quality good. The third term characterizes consumer surplus when $x$ consumers want the good and only $q_{h}+q_{l}<x$ are available. In this case only consumers whose valuations are sufficiently high get the good, and of those, $q_{l}$ consumers get the low quality good. The marginal consumer in state $x$ is defined by

$$
q_{h}+q_{l}=[1-H(v)] x,
$$

or

$$
v=H^{-1}\left(1-\frac{q_{h}+q_{l}}{\underline{x}}\right) .
$$

The first order conditions are

$$
\begin{aligned}
& -\int_{\max \left(q_{h}+q_{l}, x\right)}^{\infty} x H^{-1}\left(1-\frac{q_{h}+q_{l}}{x}\right) h\left(H^{-1}\left(1-\frac{q_{h}+q_{l}}{x}\right)\right) \frac{d H^{-1}\left(1-\frac{q_{h}+q_{l}}{x}\right)}{d q_{h}} f(x) d x \\
& \quad+\int_{\max \left(q_{h}, \underline{x}\right)}^{\max \left(q_{h}+q_{l}, \underline{x}\right)} \\
& s f(x) d x-c_{h}=0
\end{aligned}
$$

and

$$
-\int_{\max \left(q_{h}+q_{l}, x\right)}^{\infty}\left[x H^{-1}\left(1-\frac{q_{h}+q_{l}}{x}\right) h\left(H^{-1}\left(1-\frac{q_{h}+q_{l}}{x}\right)\right) \frac{d H^{-1}\left(1-\frac{q_{h}+q_{l}}{x}\right)}{d q_{h}}-s\right] f(x) d x-c_{l}=0
$$

or

$$
\int_{\max \left(q_{h}+q_{l}, \underline{x}\right)}^{\infty} H^{-1}\left(1-\frac{q_{h}+q_{l}}{x}\right) f(x) d x+s\left[F\left(\max \left(q_{h}+q_{l}, \underline{x}\right)\right)-F\left(\max \left(q_{h}, \underline{x}\right)\right)\right]=c_{h}
$$

and

$$
\int_{\max \left(q_{h}+q_{l}, \underline{x}\right)}^{\infty} H^{-1}\left(1-\frac{q_{h}+q_{l}}{x}\right) f(x) d x-s\left[1-F\left(\max \left(q_{h}+q_{l}, \underline{x}\right)\right)\right]=c_{l} .
$$


The social cost of high quality capacity is set equal to the marginal consumer's expected valuation for high quality, when the marginal consumer exists, plus the social value of switching a consumer from low quality to high quality when the marginal consumer does not exist but the high quality good is scarce. The social cost of low quality capacity is set equal to the expected valuation of the marginal consumer for the low quality good.

We can rewrite the complementary slackness conditions as

$$
G\left(q_{h}+q_{l}\right)+s\left[F\left(\max \left(q_{h}+q_{l}, \underline{x}\right)\right)-F\left(\max \left(q_{h}, \underline{x}\right)\right)\right] \leq c_{h}, q_{h} \geq 0
$$

and

$$
G\left(q_{h}+q_{l}\right)-s\left[1-F\left(\max \left(q_{h}+q_{l}, \underline{x}\right)\right)\right] \leq c_{l}, q_{l} \geq 0 .
$$

where

$$
G(z)=\int_{\max (z, \underline{x})}^{\infty} H^{-1}\left(1-\frac{z}{x}\right) f(x) d x .
$$

is the $z$ th consumer's expected valuation for quality and since $G(z) /\left[1-F\left(\max \left(q_{h}, \underline{x}\right)\right)\right]$ is the probability the $z$ th consumer exists, $G(z) /[1-F(\max (z, \underline{x}))]$ is the $z$ th consumer's expected valuation for quality conditional on there being $z$ consumers.

Proposition 6 gives necessary and sufficient conditions for two products to be produced. 
Proposition 6: If $G(\underline{x}) \leq c_{l}$, or if $G(\underline{x})>c_{l}$ and

$$
\frac{c_{l}}{G\left(q_{h}^{*}\right) /\left[1-F\left(\max \left(q_{h}^{*}, \underline{x}\right)\right)\right]-s} \geq \frac{c_{h}}{G\left(q_{h}^{*}\right) /\left[1-F\left(\max \left(q_{h}^{*}, \underline{x}\right)\right)\right]},
$$

then only the high quality good is produced. If $G(\underline{x})>c_{l}$ and

$$
\frac{c_{l}}{G\left(q_{h}^{*}\right) /\left[1-F\left(\max \left(q_{h}^{*}, \underline{x}\right)\right)\right]-s}<\frac{c_{h}}{G\left(q_{h}^{*}\right) /\left[1-F\left(\max \left(q_{h}^{*}, \underline{x}\right)\right)\right]},
$$

then both good are produced.

Proof: If $G(\underline{x}) \leq c_{l}$, then the second complementary slackness condition implies that either $q_{l}=0$ or $G\left(q_{h}+q_{l}\right)-s\left[1-F\left(\max \left(q_{h}+q_{l}, \underline{x}\right)\right)\right]=c_{l} \geq G(\underline{x})$. The later implies $q_{h}+q_{l} \leq \underline{x}$ since $G$ is an increasing function. So either $q_{l}=0$ or $q_{h}+q_{l} \leq \underline{x}$. Suppose $q_{l}=0$. Then $G\left(q_{h}\right) \leq c_{h}$ so from the complementary slackness conditions it follows that $q_{h}>0$. Alternatively, suppose $q_{h}+q_{l} \leq \underline{x}$. Then $F\left(\max \left(q_{h}+q_{l}, \underline{x}\right)\right)=F\left(\max \left(q_{h}, \underline{x}\right)\right)=0$ and the complementary slackness conditions become

$$
G\left(q_{h}+q_{l}\right) \leq c_{h}, q_{h} \geq 0,
$$

and

$$
G\left(q_{h}+q_{l}\right) \leq c_{l}+s, q_{l} \geq 0
$$

Since $c_{l}+s>c_{h}, G\left(q_{h}+q_{l}\right) \leq c_{h}$ implies $G\left(q_{h}+q_{l}\right)<c_{l}$, so $q_{l}=0$. Hence, if $G(\underline{x}) \leq c_{l}$ then only the high quality good is produced.

We now claim that if $G(\underline{x})>c_{l}$ and

$$
1-F\left(\max \left(q_{h}^{*}, \underline{x}\right)\right)<\frac{c_{h}-c_{l}}{s}
$$


then both goods are produced. Suppose these conditions are true and only high quality goods are produced. Then

$$
G\left(q_{h}^{*}\right)=\int_{\max \left(q_{h}^{*}, \underline{x}\right)}^{\infty} H^{-1}\left(1-\frac{q_{h}^{*}}{x}\right) f(x) d x=c_{h}
$$

and from the complementary slackness conditions

$$
G\left(q_{h}^{*}\right)-s\left[1-F\left(\max \left(q_{h}^{*}, \underline{x}\right)\right)\right] \leq c_{l}
$$

which implies

$$
c_{h}-s\left[1-F\left(\max \left(q_{h}^{*}, \underline{x}\right)\right)\right] \leq c_{l}
$$

and equivalently

$$
1-F\left(\max \left(q_{h}^{*}, \underline{x}\right)\right) \geq \frac{c_{h}-c_{l}}{s},
$$

which is a contradiction. So both goods are produced.

Note that $G\left(q_{h}^{*}\right)=c_{h}$ implies

$$
\left[1-F\left(\max \left(q_{h}^{*}, \underline{x}\right)\right)\right]=\frac{c_{h}}{G\left(q_{h}^{*}\right) /\left[1-F\left(\max \left(q_{h}^{*}, \underline{x}\right)\right)\right]} .
$$

So

$$
\begin{aligned}
& 1-F\left(\max \left(q_{h}^{*}, \underline{x}\right)\right)<\frac{c_{h}-c_{l}}{s}, \\
& c_{l}<G\left(q_{h}^{*}\right)-s\left[1-F\left(\max \left(q_{h}^{*}, \underline{x}\right)\right)\right], \\
& \left.c_{l}<\left[1-F\left(\max \left(q_{h}^{*}, \underline{x}\right)\right)\right] \frac{G\left(q_{h}^{*}\right)}{\left[1-F\left(\max \left(q_{h}^{*}, \underline{x}\right)\right)\right]}-s\right], \\
& \frac{c_{l}}{G\left(q_{h}^{*}\right) /\left[1-F\left(\max \left(q_{h}^{*}, \underline{x}\right)\right)\right]-s}<\left[1-F\left(\max \left(q_{h}^{*}, \underline{x}\right)\right)\right],
\end{aligned}
$$


and

$$
\frac{c_{l}}{G\left(q_{h}^{*}\right) /\left[1-F\left(\max \left(q_{h}^{*}, \underline{x}\right)\right)\right]-s}<\frac{c_{h}}{G\left(q_{h}^{*}\right) /\left[1-F\left(\max \left(q_{h}^{*}, \underline{x}\right)\right)\right]}
$$

are equivalent. It follows that both goods are produced if $G(\underline{x})>c_{l}$ and

$$
\frac{c_{l}}{G\left(q_{h}^{*}\right) /\left[1-F\left(\max \left(q_{h}^{*}, \underline{x}\right)\right)\right]-s}<\frac{c_{h}}{G\left(q_{h}^{*}\right) /\left[1-F\left(\max \left(q_{h}^{*}, \underline{x}\right)\right)\right]} .
$$

Note that $q_{h}^{*} \leq \underline{x}$ is a necessary condition for production of the low quality good.

If at the optimal single product production level, every unit of the high quality good produced is consumed in every demand state, then the low quality good will not be produced. Multiple product production is optimal when capacity (or inventory) is not always fully utilized. Numerous classes of demand functions, such as isoelastic and Cobb-Douglas, have the property that demand approaches infinity as price goes to zero which implies $\underline{x}=\infty$. In this case, it is clear that $q_{h}^{*}<\underline{x}$ and production is always fully utilized so only one product would be produced.

The necessary and sufficient conditions under which a social planner would choose to produce both high and low quality products are different from the conditions under which a monopolist or a competitive market with price rigidities (Sections 3.2 and 3.3) would produce both products. For a monopolist this is clear because the decision depends on the preferences of the marginal consumers and the monopolist will clearly distort price and sell to fewer consumers. Similarly, under two of the competitive models we analyze, prices are rigid and the resulting market distortions will impact the product line decision. In each of these models, price rigidities increase the likelihood that capacity is underutilized and hence increases the value of producing both products. Under market clearing prices, the equilibrium product line decision will be the same as in Proposition 6 . This is fairly easy to see since the competitive market with market clearing prices allocates the good in the same way that the social planner does. 


\section{Monopoly with Full Product Line}

In this section we generalize the two-product model by allowing the firm to offer a continuum of vertically differentiated product varieties. We consider explicitly only the monopolist's decision, however generalizations of the other models are also feasible and based on the analysis of the monopoly case we briefly discuss the various competitive models and the complex forces that will drive product line decisions in those environments.

As before, let $f(x)$ denote the probability density function associated with the random variable $x$, the number of identical consumers willing to buy one unit of output (one good), on the support $[\underline{x}, \bar{x}] \subset \mathfrak{R}^{+}$and suppose $\underline{x}>0$. Let $F(x)$ denote the associated cumulative distribution function.

Let $v$ denote consumers' willingness to pay. Let $c(v)$ denote the cost of producing one unit of the product when quality is $v$. We assume $c(0)=0$ and $c^{\prime}(0)<1$. We also assume that there exists some $\bar{v}$ such that $v-c(v)<0$ for all $v>\bar{v}$. Let $v^{*}=\operatorname{argmax}(v-c(v))$. Clearly,

Proposition 7: When demand is certain, the monopolist chooses product quality $\tilde{v}=v^{*}$, produces $q=x$ units, and sets its price equal to $v^{*}$.

We now turn to the case where demand is uncertain.

\section{Single Product Monopolist}

Suppose that the firm is able to produce only one product. Which level of product quality would the firm choose? The firm chooses its price, quantity, and quality to maximize profits. Clearly the firm sets $p_{h}=v$, whether prices are set before or after demand is realized, so we can write the firm's problem as

$$
\max _{v, q} \int_{0}^{q} v x f(x) d x+\int_{q}^{\infty} v q f(x) d x-q c(v) .
$$

The first order conditions are 


$$
v[1-F(q)]-c(v)=0
$$

and

$$
\int_{0}^{q} x f(x) d x+\int_{q}^{\infty} q f(x) d x-q c^{\prime}(v)=0
$$

Rewriting these expressions, the firm's optimal inventory is given by

$$
\left[1-F\left(q^{*}\right)\right]=\frac{c(v)}{v}
$$

and its optimal quality is given by

$$
c^{\prime}(\tilde{v})=\frac{\int_{0}^{q} x f(x) d x+\int_{q}^{\infty} q f(x) d x}{q} .
$$

This establishes the following two results:

Proposition 8: When demand is uncertain and the firm is constrained to choose a single product variety, then the product quality chosen satisfies $\tilde{v}<v^{*}$.

Proposition 9: As the demand uncertainty increases, the monopolist's choice of product quality, $\tilde{v}$, falls.

\section{The Multi-Product Monopolist}

We now suppose that the monopolist can produce an arbitrary amount of each quality. Without loss of generality (since the firm offers a continuum of product qualities), we assume it sets a uniform price for each quality.

The following Lemma simplifies the statement of the firm's optimization problem. We show that the monopolist sets $p(v)=v$ for all of the products it offers and that purchase decisions are ex post efficient. Once again, this is very intuitive. Since these prices are feasible, the firm can easily induce consumers' to make ex post efficient 
purchasing decisions, and the firm captures the entire surplus, it is impossible for the monopolist to achieve any higher ex post profits.

Lemma: Given its inventory, the monopolist sets $p(v)=v$ for all of the products it produces, and in equilibrium consumers buy goods in decreasing order of quality (highest quality goods stock out first).

Proof: If consumers strictly prefer some goods to others, then there must be at least one good whose price the firm can increase without affecting the order in which consumers make their purchases or the total volume of their purchases, and would therefore increase profits. Since this is a contradiction, consumers must be indifferent between all goods.

If consumers are indifferent between the goods then clearly the price and quality ranking of the goods must be the same and it follows that consumers must buy the highest priced (highest quality) good first, and consume the goods in decreasing order of price. If not, then by lowering the prices of all of its goods by a small, systematical different, amount, the firm could induce consumers to reorder there purchases in decreasing order of price which strictly increases the firm's expected profit.

The firm must set the price of its lowest quality units equal to consumers' valuations since otherwise raising this price would have no impact on the volume or order of product sales and would strictly increase profits. And since consumers are indifferent between the goods, it follows that the prices for all products must equal consumers' valuations.

The firm's problem is further simplified if we express the decision variable as the quality of each unit of the firm's output rather than the amount of its output to offer at each quality level. Define $v(x)$ to be the quality of the good purchased and consumed by 
the marginal consumer when $x$ consumers demand the good. So $c(v(x))$ is the ex ante cost of producing the marginal unit consumed in state $x$. It follows directly from the lemma that $v(x)$ is non-increasing in $x$, and therefore that $c(v(x))$ is non-decreasing in $x$.

The firm's problem is to choose its inventory and the product quality of each unit of its inventory. Let $Q$ denote the firm's inventory which is clearly finite, so the firm chooses $Q$ and $v(x)$ on $[0, Q]$ to maximize

$$
\int_{0}^{Q} v(x)(1-F(x)) d x-\int_{0}^{Q} c(v(x)) d x
$$

subject to the constraint that $v(x)$ is non-increasing.

Proposition 10: When demand is uncertain, the optimal range of qualities for the firm is $\left[\hat{v}, v^{*}\right]$.

Proof: Suppose the constraint does not bind. Then it is clear that the firm's optimization can be solved by point-wise maximization. The first order conditions are

$$
c^{\prime}(v(x))=1-F(x)
$$

for all $x \in[0, Q]$ and

$$
\frac{c(v(Q))}{v(Q)}=1-F(Q)
$$

Equation $(*)$ implies that $v(0)=v^{*}=\arg \max (v-c(v))$. Combining $(*)$ and $(* *)$ yields

$$
c^{\prime}(v(Q))=\frac{c(v(Q))}{v(Q)} .
$$

So from the definition of $\hat{v}$,

$$
v(Q)=\hat{v}=\arg \min \frac{c(v)}{v} .
$$


Since, $c^{\prime \prime}>0$, and $(*)$ implies

$$
c^{\prime \prime}(v(Q)) v^{\prime}(Q)=-f(x),
$$

it follows that $v(x)$ is strictly decreasing and the constraint is not binding. So the optimal range of qualities is $\left[\hat{v}, v^{*}\right]$.

The proposition establishes that the highest quality product that the firm produces is the product that would be offered if demand were certain. That is, the highest quality offered is the one that maximizes surplus (and the monopolist's margin) conditional on sale. The lowest quality offered is the one that maximizes the monopolist's percentage markup.

Note that the range of qualities is always finite, as long as $c\left(v^{*}\right)<v^{*}$, because when the cost function is continuous there always exists a finite interval on which $c(v) / v$ is increasing and $c-v$ is decreasing. In other words, there exists some $v<v^{*}$ such that

$$
\frac{c(v)}{v}<\frac{c\left(v^{*}\right)}{v^{*}} .
$$

As demand becomes more and more certain, the range of products offered remains the same. This is empirically counterintuitive. However, this model ignores the fixed costs associated with product variety. While the optimal product variety is independent of the demand uncertainty, the benefits of product variety diminish as demand becomes more certain. So if fixed costs of product variety were included in the model, then variety would diminish.

For brevity we do not replicate these results for the three competitive models discussed in Section 3. However it is clear that the monopolist is once again extracting the entire consumer surplus, so the monopoly outcome, social planner outcome, and the market clearing price outcome are clearly the same. Because consumers have 
homogeneous valuations, the other two competitive models also yield the same market allocation.

\section{Conclusion}

We have shown that demand uncertainty is an explanation for vertical product differentiation even when consumers have ex post identical tastes. Demand uncertainty makes it possible that not all inventory or capacity is utilized, and as a consequence, firms find it optimal to respond to sell low cost, low quality products in addition to high cost, high quality ones. In practice underutilization of inventory is much more likely when firms prices are rigid. Therefore, all else equal, we expect that we see a greater range of product qualities in such cases.

Future work should consider product line choice when the manufacturer and the retailer are different firms. In this case, a monopoly manufacturer of a high quality good can choose to extract rents from his retailer either directly through a higher price, or indirectly by being the sole supplier of the low quality good and earning an additional margin when a low quality sale is made. This second approach is likely to be more efficient than the first, because it avoids a marginal price distortion. This suggests that simple extensions of our model will provide an explanation for manufacturers' use of full-line forcing.

We believe that this work should have a direct impact on the empirical literature on product differentiation and price discrimination. Our model predicts higher absolute markups and lower percentage markups for high quality products in both competitive and monopoly markets, even when consumers have ex post identical preferences for product quality. The model is empirically relevant for any market in which consumer substitute between high and low quality, market demand is uncertain, and market clearing spot prices do not guarantee that firms' inventory or capacity is fully utilized. 
Empirical testing of the model would require careful attention to the measurement of margins, turnover, shelf space restrictions, competitive conditions in retailing and manufacturing, and the use of full line forcing, as well as to the existence of customers with different relative valuations over quality. Perhaps the most direct existing studies relevant to our model involve a study of grocery stores, which, for a wide variety of products, stock both high quality national brands and low quality private labels. The evidence seems to support our model's main predictions. For a wide variety of products (e.g., tooth brushes, toothpaste, soft drinks, crackers, soups, cereals, etc) grocery stores earn a higher percentage margins on private labels than on national brands, while the absolute margin (especially after adjusting for turnover) is generally higher on the national brands. ${ }^{3}$ But these studies should be viewed as only suggestive of the model's applicability, and more carefully designed studies across a variety of different industries would be necessary to full test the applicability of the model's predictions.

${ }^{3}$ See Barsky, et. al. (2001), Hock and Banjier (1993), Ailawadi (2002), Salman and Cmar, 1987, Supermarket Strategic Alert (2002), Brady et. al. (2003), Berges-Sennou et. al. (2003). 


\section{References}

Ailawadi, Kusum, and Bari Harlam, 2002, "The Effect of Store Brands on Retailer Profitability: An Empirical Analysis," Working Paper 02-06, Tuck School of Business at Dartmouth.

Barsky, Robert, Mark Bergen, Shantanu Dutta, and Deniel Levy, 2001, "What can the Price Gap Between Branded and Private Label Products Tell us about Markups?," NBER Working Paper 8426, August.

Bassok, Yehuda, Ravi Anupindi, Ram Akella, 1999, "Single-Period Multi-product Inventory Models With Substitution," Operations Research, Volume: 47. JulyAugust 1999, Number: 4. pp. 0632-0642.

Berges-Sennou, Fabian, Philippe Bontems, and Vincent Requillart, 2003, "Economic Impact of the Development of Private Labels," Conference of the Food System Research Group, University of Wisconsin, Madison, June.

Brady, Lucy, Aaron Brown, and Barbara Hulit, (2003) "Private Label: Threat to Manufacturers, Opportunity for Retailers," available at BetterManagement.com.

Carlton, Dennis W., (1978), "Market Behavior with Demand Uncertainty and Price Inflexibility," American Economic Review, September, 68, pp. 571-587.

Dana, James D. "Advance-Purchase Discounts and Price Discrimination in Competitive Markets" Journal of Political Economy, Vol.106, Number 2, April 1998, 395-422.

Dana, James, "Equilibrium Price Dispersion Under Demand Uncertainty: The Roles of Costly Capacity and Market Structure," RAND Journal of Economics, 2000.

Deneckere and Peck "Competition over Price and Service Rate when Demand Is Stochastic: A Strategic Analysis.” RAND Journal of Economics, Vol. 26 (1995), pp. 148-161.

Eaton and Lipsey, "Product Differentiation," in Handbook of Industrial Organization, Vol. 1, North-Holland, 1989.

Eden, Benjamin, "Seemingly Rigid Prices,” The University of Haifa, April 2002.

Eden, Benjamin (1990), "Marginal Cost Pricing When Spot Markets Are Complete," The Journal of Political Economy, Vol. 98, No. 6. (Dec., 1990), pp. 1293-1306.

Hoch, Stephen, and Sumeet Banerji, 1993, "When Do Private Labels Succeed?," Sloan Management Review, Summer, pp. 57-77.

Lancaster, Kevin, 1990, “The Economics of Product Variety: A Survey”, Marketing Science, vol. 9, no. 3, Summer, 189-206. 
Mahajan and van Ryzin (1998) "Stocking Retail Assortment under Dynamic Consumer Substitution," Operations Research, 49(3), May-June, pp. 334-351.

Mussa, Michael and Sherwin Rosen, 1978, "Monopoly and Product Quality," Journal of Economic Theory, 18, pp. 301-317.

Prescott (1975), "Efficiency of the Natural Rate," Journal-of-Political-Economy, December, pp. 1229-1235.

Salmon, Walter J, and Karen Cmar, 1987, "Private Labels Are Back in Fashion," Harvard Business Review, May/June, p. 99.

Shepard, Andrea, "Price Discrimination and Retail Configuration," Journal-of-PoliticalEconomy, 99(1), February 1991, pages 30-53.

Smith and Agrawal, (2000), "Management on Multi-item retail inventory systems with demand substitution," Operations Research, 48, pp. 50-64.

"Supermarket Strategic Alert Special Report 2002, Branding and Private Labels," Pollack Associates, 2002,

van Ryzin and Mahajan, (1999), "On the relationship between inventory costs and variety benefits in retail assortments," Management Science, 45, pp. 1496-1509. 